\section{Alterações hematológicas associadas ao uso de olanzapina após neutropenia por clozapina}

\section{Hematological alterations associated to olanzapine use after clozapine-induced neutropenia}

\section{Sr. Editor}

O uso da clozapina é limitado pela ocorrência de agranulocitose em 0,5-2\% dos pacientes. A olanzapina pode ser uma alternativa nestes casos; porém, alterações hematológicas (leucopenia, neutropenia, agranulocitose) relacionadas ao uso de olanzapina têm sido descritas. Há relatos de alterações quando a olanzapina foi usada isoladamente ${ }^{1}$ ou associada com haloperidol, ${ }^{2}$ após neutropenia por risperidona ${ }^{3}$ e quando a ziprasidona foi empregada após neutropenia por olanzapina. ${ }^{4}$ Há ainda diversos relatos de prolongamento ou recidiva por uso de olanzapina, de alterações induzidas pela clozapina. ${ }^{1,5}$ Descrevemos o caso de um paciente que desenvolveu neutropenia com clozapina e, posteriormente, com olanzapina, mas que tolerou bem a reintrodução desta, dois meses após sua suspensão.

Paciente masculino, 32 anos, diagnóstico de esquizofrenia paranóide refratária, apresentou neutropenia (LT: 4440; SEG: 1020) após sete dias recebendo dose de $200 \mathrm{mg} /$ dia de clozapina. O tratamento foi interrompido e em seis dias observou-se recuperação hematológica (LT: 6800; SEG: 3830), que se manteve. Trinta dias após a interrupção da clozapina foi iniciada olanzapina até 10 mg/dia, acompanhada por hemogramas seriados. Após 11 dias, o paciente apresentou novamente redução dos neutrófilos (LT: 4900; SEG: 1670). A olanzapina foi suspensa em virtude da neutropenia prévia e do decréscimo relativamente rápido dos neutrófilos. O paciente continuou em monitoramento hematológico, com contagem de reticulócitos para avaliação da função medular. Foi feita propedêutica que descartou outras causas de neutropenia (sorologia para sífilis, hepatite B e C, HIV, PCR, VHS, FAN). Foi introduzida risperidona até $6 \mathrm{mg} / \mathrm{dia}$ e, em 30 dias, o padrão hematológico basal estava restabelecido (LT: 6040; SEG: 2430). Após 42 dias sem resposta satisfatória e diante da gravidade do quadro psiquiátrico, a olanzapina foi reintroduzida até $30 \mathrm{mg} / \mathrm{dia}$ com acompanhamento hematológico, que não revelou novas alterações. Atualmente, após um ano, o paciente permanece estável em uso de olanzapina.

Mecanismos tóxicos, imunológicos e genéticos têm sido relacionados aos efeitos hematológicos da olanzapina. ${ }^{1}$ Thangadurai et al. relataram caso de paciente em uso de olanzapina que apresentou recidiva de neutropenia após primeiro episódio em uso de clozapina. ${ }^{5}$ Como este paciente já havia usado olanzapina sem complicações hematológicas, estes autores sugerem que o uso da clozapina pode ter sensibilizado o sistema imunológico, tornando o paciente susceptível à neutropenia induzida pela olanzapina. Isso é compatível com a semelhança molecular dos dois fármacos. Contudo, outros mecanismos não podem ser descartados, considerando os relatos de alterações hematológicas por olanzapina isoladamente ${ }^{1}$ e aqueles sugestivos de reação cruzada da olanzapina com outros antipsicóticos. ${ }^{2-4}$
O presente relato é compatível com a hipótese de Thangadurai et al. ${ }^{5}$ descrita acima, mas sugere que a susceptibilidade à neutropenia após exposição à clozapina pode ser transitória, de modo que o risco hematológico da olanzapina decresceria à medida que o tempo decorrido após a suspensão da clozapina aumentasse. Sugerimos que pacientes que desenvolverem alterações hematológicas com clozapina tenham exames hematológicos monitorizados caso façam tratamento subseqüente com olanzapina, pois há evidências de risco aumentado de neutropenia. Embora novos estudos sejam necessários, diante da transitoriedade das alterações hematológicas, a reintrodução da olanzapina pode ser considerada.

\section{Carolina Gama Cabral, Maila de Castro Lourenço das Neves}

Hospital de Ensino Instituto Raul Soares, Fundação Hospitalar do Estado de Minas Gerais (FHEMIG), Belo Horizonte (MG), Brasil

Rodrigo Nicolato Hospital de Ensino Instituto Raul Soares, Fundação Hospitalar do Estado de Minas Gerais (FHEMIG), Belo Horizonte (MG), Brasil Universidade José do Rosário Vellano (Unifenas), Belo Horizonte (MG), Brasil

Hélio Lauar

Hospital de Ensino Instituto Raul Soares, Fundação Hospitalar do Estado de Minas Gerais (FHEMIG), Belo Horizonte (MG), Brasil Pontifícia Universidade Católica de Minas Gerais (PUC$M G)$, Belo Horizonte (MG), Brasil

João Vinícius Salgado Hospital de Ensino Instituto Raul Soares, Fundação Hospitalar do Estado de Minas Gerais (FHEMIG), Belo Horizonte (MG), Brasil Universidade FUMEC, Belo Horizonte (MG), Brasil

Financiamento: Inexistente

Conflito de Interesses: Inexistente

Referências

1. Duggal HS, Gates C, Pathak PC. Olanzapine-induced neutropenia: mechanism and treatment. J Clin Psychopharmacol. 2004;24(2):234-5.

2. Abdullah N, Voronovitch L, Taylor S, Lippmann S. Olanzapine and haloperidol: potential for neutropenia? Psychosomatics. 2003;44(1):83-4.

3. Gajwani P, Tesar GE. Olanzapine-induced neutropenia. Psychosomatics. 2000;41(2):150-1.

4. Montgomery J. Ziprasidone-related agranulocytosis following olanzapine-induced neutropenia. Gen Hosp Psychiatry. 2006;28(1):83-5

5. Thangadurai P, Jyothi KS, Gopalakrishnan R, Kuruvilla A, Jacob KS. Reversible neutropenia with olanzapine following clozapine-induced neutropenia. Am J Psychiatry. 2006;163(7):1298. 